\title{
JobStart Provides Preemployment Education for Welfare to Work Clients: Methods and Outcomes
}

\author{
Elizabeth B. Bolton \\ Professor of Community Development \\ Department of Family, Youth and Community Sciences
}

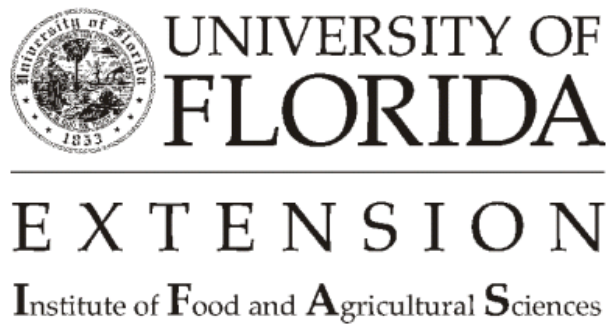


The Institute of Food and Agricultural Sciences at the University of Florida has undertaken a training initiative with a Welfare to Work (WtW) grant from the Agency for Workforce Innovation (formerly Florida Department of Labor \& Employment Security). Under this initiative, the IFAS statewide Cooperative Extension Service network is delivering training programs designed to help move hard-to-serve welfare recipients into unsubsidized employment and economic self-sufficiency.

\section{Background}

Florida's welfare reform law took effect in October, 1996. The law requires able-bodied welfare recipients to find gainful employment. In most cases cash assistance has a lifetime limit of four years with no more than two years assistance out of any consecutive six months, making it imperative that welfare recipients look for, obtain, and maintain unsubsidized employment.

\section{The Need}

Many welfare recipients want a job; others have no desire to work; many have worked at one time during their lives and others have never worked. These people all have one thing in common. They no longer have an alternative to working; they must find gainful employment. Finding a job and keeping it is not easy given the situations of many WtW clients. Many have no experience with any kind of paid employment, or if they have worked cannot provide references to that employment. If they do find a job, keeping it is another challenge. There is a high turnover rate for WtW employees, primarily because they exhibit poor work habits and attitudes, lack work experience and are unable to adequately present themselves to a potential employer.

\section{JobStart - A Response to the Need}

Florida Cooperative Extension is responding to the plight of WtW clients through the UF/IFAS Welfare to Work Initiative. The JobStart program is designed to help adults reach their potential of finding the right job for their skills and experience by providing the training necessary to successfully contact potential employers and develop the skills to stay on the job once they are hired. JobStart will compliment other programs offered by the UF/IFAS initiative, specifically:

Food Safety at the Tip of Your Fingers - a program designed to provide participants with the skills and knowledge needed for entry level positions in the food service industry.

The Elder Companion - a program designed to provide participants with the skills and knowledge needed to find employment as caregivers or companions to the elderly.

Planting the Seeds for Success - a program designed to provides participants with the skills and knowledge needed for entry level positions in the horticultural industry.

A Green Future - a program designed to provide participants with the skills and knowledge to work or start their own business in the lawn maintenance and/or landscaping industry.

\section{The JobStart Curriculum}

The JobStart curriculum was developed by Dr. Elizabeth Bolton, Professor of Community Development. Originally developed to address the needs of public housing residents, the curriculum has been adapted and expanded to meet the needs of hard-to-serve WtW clients.

Participants will receive classroom training for specific skills needed to apply for and keep a job. This training is a 16-hour structured learning experience covered in a four or eight week period, taught for a two hour time period once or twice a week. Learning strategies include discussion, role play, oral presentations, guest speakers and 
written assignments. Other information essential to participants' success in the workforce such as knowledge of potential employers, the availability of childcare services, and local transportation networks also form an integral part of the training.

Upon successful completion of JobStart, participants will receive a certificate which can be presented to prospective employers as proof of training.

\section{Modules and Objectives}

The modules and their objectives are as follows:

Part 1 - Getting to Know Yourself. Participants develop a personal inventory that will help them learn about their strengths, weaknesses, and interests.

Objective 1. Participants will recognize the importance of a personal inventory in the interview process. Objective 2. Participants will complete a personal inventory for their own use during the interview process.

Objective 3. Participants will be able to respond to interview questions about themselves with positive, well prepared answers.

Objective 4. Participants will be able to recognize their own values and understand how they impact their work life.

Part 2 - The Right Job - Just for You. Participants learn to set goals and discover the important steps for searching successfully for the job best suited to themselves.

Objective 1. Participants will determine the career path that best suits their needs and that will offer the best chance of success.

Objective 2. Participants will be able to write measurable long and short term goals that will lead them to success in the work world.

Objective 3. Participants will write an employability plan that includes all the steps they will need to take in order to win the job they want.

Part 3 - Marketing Yourself. Participants learn proven ways to help them connect with the right job, company or employer.

Objective 1. Participants will be able to recognize their own network and be able to use it effectively to find a job.

Objective 2. Participants will develop a personal plan for using the telephone to locate and secure employment.

Objective 3. Participants will be able to write a sales letter that will act as an introductory device to prospective employers.

Part 4 - Preparing Your Resume. Participants learn the proper way to prepare a resume that fits them to the job they are interested in.

Objective 1. Participants will be able to recognize a quality resume using the provided checklists and evaluation handouts.

Objective 2. Participants will be able to develop a professional and effective resume for use in their job search.

Objective 3. Participants will be able to recognize the best persons to use as references for a job and to develop a reference list. 
Part 5 - Writing the Cover Letter. Participants learn how to write a cover letter that tells a prospective employer what to look for in the resume.

Objective 1. Participants will be able to recognize a quality cover letter using the provided checklists and evaluation handouts and how to write a cover letter that tells a prospective employer what to look for in a resume.

Objective 2. Participants will write a professional and effective cover letter for use in their job search.

Part 6 - Planning the Interview. Participants learn how to anticipate and respond to interview questions, how to dress, and the importance of body language.

Objective 1. Participants will be able to prepare themselves to successfully conduct an employment interview.

Objective 2. Participants will be able to respond to common interview questions and also be able to deal with off-limit questions in a tactful manner.

Objective 3. Participants will recognize proper interview attire that gives a good impression to the employer.

Objective 4. Participants will understand the importance of body language in the interview.

Part 7 - Job Seeking Strategies. Participants receive information on the best ways to look for a job and fill out an application.

Objective 1. Participants will be aware of the various types of job seeking strategies such as help wanted ads, employment agencies, and temporary employment services and understand how to use them effectively.

Objective 2. Participants will be able to complete an employment application in a professional manner.

Part 8 - Staying on the Job Once You Are Hired. Participants learn how to become a successful employee who works well with others and can look forward to advancement.

Objective 1. Participants will be able to identify positive work attitudes and apply them to their own behavior in the workplace.

Objective 2. Participants will be able to apply coping behaviors when dealing with difficult people.

Objective 3. Participants will be able to identify stress in their lives and use stress relieving techniques to deal with it.

\section{Outreach and Dissemination}

WtW clients receive JobStart training through regularly scheduled sessions conducted by county faculty and other program trainers. The project director and project coordinator train local trainers in program delivery and provide all necessary resources.

In order to insure every effort has been made to introduce JobStart as a comprehensive program for job preparation, County Extension faculty has worked with other identified community organizations working with regional initiatives. This has been accomplished through collaboration with the WtW regional director and IFAS regional representatives.

\section{Evaluation}

A procedure for evaluating the results of the JobStart training has been established based on the following predetermined criteria: 


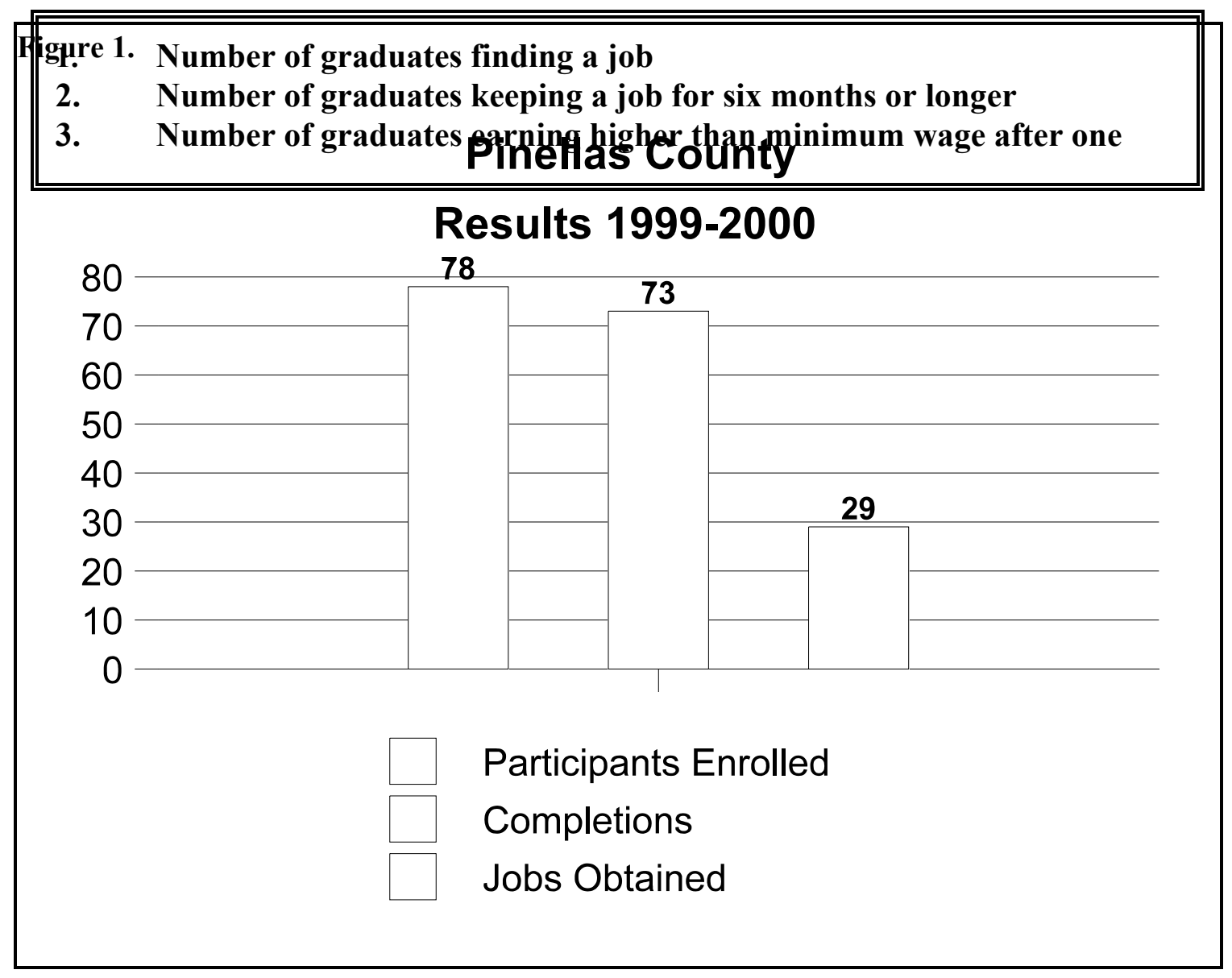

A database has been developed with information about every WtW client who has participated in the series. Data collection, evaluation and reporting is coordinated with data bases currently in use by other state, regional and local agencies involved in the initiative. A system for follow up has been developed to ascertain what effects, positive and/or negative JobStart has had on the WtW client. Some of the clients may be counseled to participate in the training a second time.

\section{JobStart in Pinellas County}

JobStart has been used extensively throughout Florida in WorkForce Districts. For example in Pinellas County, a partnership with Pinellas County Extension, Regional WorkForce Development Board, and the Pinellas County Park Department delivered the JobStart program to a targeted audience of Welfare to Work clients. The partnership offered a unique situation in that there was no waiting for a job, i.e. the jobs were available when the client finished the course work. Further, one of the barriers to success, transportation, was obviated by having a cab ride to and from the class. The transportation was paid for by the WorkForce Board. An additional incentive was free childcare, also provided by the WorkForce Board.

The clients, identified by the WorkForce Board as Welfare to Work eligible, were applying for entry level positions that filled the needs of the Park Department which was experiencing a high turnover of entry level positions. If an employee was successful in his/her application the position included full benefits. The Pinellas Program was delivered in eight lessons of two hours each followed by a money management course which also included eight lessons of two hours. Each course met twice a week for four weeks.

During 1999 and 2000, 78 Welfare to Work clients participated in the JobStart class in Pinellas County with 73 completing the course. Of this group, 29 had obtained jobs as of the end of 2000 making an average wage of 
$\$ 6.90$ with benefits of approximately $42 \%$ of this amount giving a value of $\$ 9.80$ per hour for these positions. A 2001 update shows that several of these JobStart Welfare to Work clients have had promotions within the Pinellas Park Department and several are now working at the Florida Botanical Garden. Further, two additional workers are now making over $\$ 10.00$ per hour. (See Figure 1).

JobStart is a competency based curriculum and seeks to deal with skills as well as attitudes. Some of the attitudes of the Pinellas class that warrant additional instruction were noted. Participants were observed to have a lack of interaction skills. This mitigated against working with others and having good relationships with a supervisor. The inability to manage time was also noted by the instructor. Personal responsibility was a topic of discussion in both JobStart and the money management course. The emphasis was on being responsible for one's own needs and to overcome the notion that everything should be provided by some agency or institution.

On the positive side, in addition to completing a course that deals specifically with getting a job and getting along with a supervisor, participants were able to develop a new set of friends who were also experiencing success for the first time in a classroom setting. Working on a personal resume was also a very positive experience in that it provided an opportunity for each participant to take a close look at his/her own personal life.

\section{JobStart in Suwannee County}

Suwannee County Extension provides another example of using the JobStart curriculum for the hard to serve client. In this county, JobStart was supplemented with literacy education when it was learned that most of the clients that were eligible for the training had deficits in one or more literacy skills. Various agencies in Suwannee County participated in recruitment. These included Suwannee County Regional Library, Suwannee Hamilton Vocational Technical School, Suwannee County Department of Children and Families, and the local High School. Each of the agencies offered access to a somewhat different client group. For example, pregnant teenagers were recruited from the high school and food stamp recipients were recruited from the Department of Children and Families. Recruitment was an issue in this program because the Regional Workforce Board was inactive in the County.

A total of 42 participants were recruited for the JobStart program in Suwannee County. Of these 27 completed the course and 13 were placed in employment. After a period of two months, as of December, 2000, ten were still employed and 4 additional participants were seeking additional education, most at the community college level. A profile of the participants for the Suwannee County JobStart program showed that there were 36 females and 6 males, with 23 of the females completing the course and 4 of the males completing. The racial breakdown of the participants showed that 18 were African American, one each Filipino and Hispanic and 22 Whites. Of the 18 African Americans, 12 completed the course and 13 of the 22 Whites completed the course. Both the Hispanic and the Filipino participants completed the course. On an average, participants were 19 years old with one child. Of the 11 finding and retaining employment, the average wage was $\$ 6.58$ per hour. (See Figure 2.)

\section{Observations and Summary}


Observations relevant to the client group and the educational environment are relevant to the JobStart program as well as other educational programs designed for the hard-to-serve client.

1. Background Checks: Many jobs available to the clients of the WtW program necessitate background checks. If the One Stop Center or the WorkForce Board could complete the background checks before the clients complete the training classes, it would be beneficial to the client and instructor. In order to intern or be job placed in hospitals, nursing homes, or schools, the background check must be completed. If the background check is completed, the WtW customer would be employable sooner. The background check would also promote good community relations and make the UF IFAS as well as the WorkForce programs more attractive to local businesses.

2. GED Program: Many of the WtW clients are school dropouts. Many of these persons would qualify as learning disabled students if they were in a public school. These clients need special attention and encouragement if they are to succeed in any employment situation. Most GED programs are too impersonal for the individual that needs

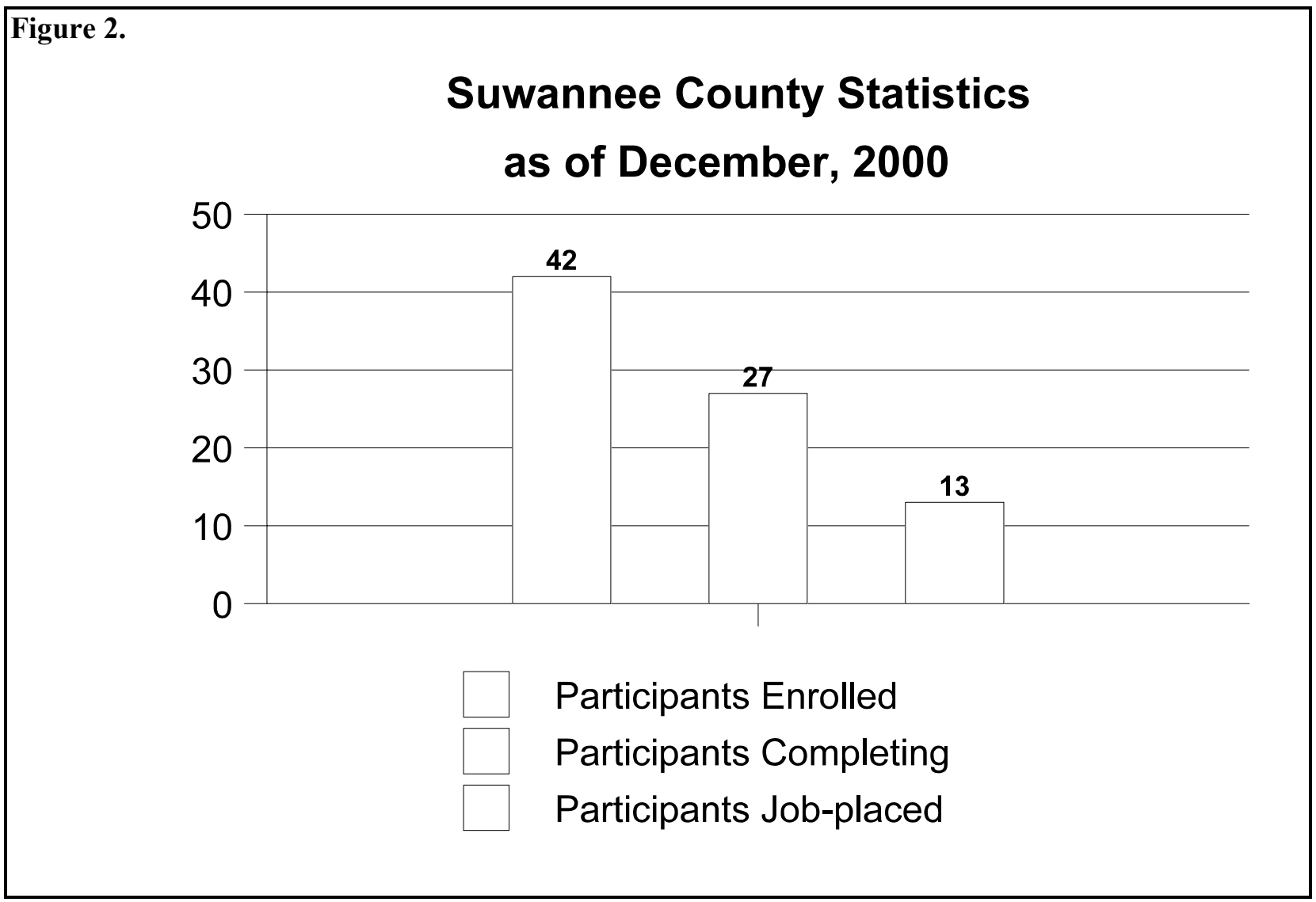

somewhat constant attention and encouragement. This kind of personal attention combined with literacy training provides a learning environment/situation that greatly enhances the probability of work attainment and retention.

3. Literacy Instruction: Instruction in reading and writing are appropriate support programs for the General Equivalency Diploma. Many clients cannot read adequately nor write well enough to complete an application for employment. To develop limited, acceptable skills, these clients need learning instruction appropriate for slower 
learning students. This instructional effort is one way to help build personal courage and self-esteem. The JobStart curriculum deals with this to some extent by using templates for composing letters, highlighted words and phrases and practice in every aspect of job application and interviewing.

4. Client Appreciation: Most of the clients who did make the classes were very appreciative of the things they learned and the personal and social gains they made. Several of clients maintain contact with the instructor as though she symbolizes an anchor for their achievement.

5. Small Classes: Small classes are a necessity for the learning disabled WtW client. Many are socially ill-at-ease and smaller groups are less threatening and are easier for establishing relationships. Small classes also make teacher relationships more personal and easier and faster to establish. A close teacher student relationship is important for completion and success. This contributes to the anchor effect noted earlier.

In summary, JobStart is a curriculum that has application for various target groups and can be used in a variety of contexts to include literacy training as in Suwannee County and preemployment as in Pinellas. While the curriculum is important, it is the skill of the instructor that makes it meaningful and relevant to the clients' needs. It is especially relevant to the many low income audiences Extension county faculty serve in a variety of programs.

\section{This report, JobStart Provides Preemployment Education for Welfare to Work Clients: Methods and}

Outcomes, is part of the UF/IFAS Welfare-to-Work Initiative (Grant \#A6218) funded by the Florida Agency for Workforce Innovation (formerly Florida Department of Labor and Employment Security). The Principal Investigator is Elizabeth B. Bolton, Professor of Community Development, Department of Family, Youth and Community Sciences. 